\title{
Confident but not theoretically grounded - experienced simulation educators' perceptions of their own professional development
}

This article was published in the following Dove Press journal:

Advances in Medical Education and Practice

20 January 2017

Number of times this article has been viewed

Renée Allvin,' Magnus

Berndtzon, ${ }^{2}$ Liisa Carlzon, ${ }^{3}$

Samuel Edelbring, ${ }^{4,5}$ Håkan

Hult, ${ }^{6}$ Magnus Hultin, ${ }^{7}$ Klas

Karlgren, ${ }^{5,8}$ Italo Masiello,

Marie-Louise Södersved

Källestedt, ${ }^{10}$ Éva Tamás ${ }^{11}$

'Clinical Skills Centre, Faculty of Medicine and Health, School of Medical Sciences, Örebro University, Örebro, ${ }^{2}$ Metodikum - Skill Centre of Medical Simulation Region County Jönköping, Jönköping, ${ }^{3}$ Simulation Centre West, Department of Research, Education and Development, Sahlgrenska University Hospital, Gothenburg, ${ }^{4}$ Department of Medical and Health Sciences, Faculty of Medicine and Health Sciences, Linköping University, Linköping, ${ }^{5}$ Department of Learning, Informatics, Management and Ethics, Karolinska Institutet, Stockholm, ${ }^{6}$ Institute of Medicine and Health, Medical Faculty, Linköping University, Linköping, ${ }^{7}$ Department of Surgical and Perioperative Sciences, Anaesthesiology and Intensive Care, Medical Faculty, Umeå University, Umeå, ${ }^{8}$ Department of Research, Education and Development and Innovation, Södersjukhuset Hospital, Stockholm, ${ }^{9}$ Department of Clinical Science and Education, Karolinska Institutet, Södersjukhuset Hospital, Stockholm, ${ }^{10} \mathrm{Clinical}$ Skills Centre, Centre for Clinical Research, Uppsala University, Västerås, "Department of Cardiovascular Diseases, Institute of Medicine and Health, Medical Faculty, University of Linköping, Linköping, Sweden

Correspondence: Renée Allvin Clinical Skills Centre, Faculty of Medicine and Health, School of Medical Sciences, Örebro University, Södra Grev Rosengatan, S-70I 85 Örebro, Sweden

Tel +46 19602 0144

Email rene.allvin@regionorebrolan.se
Background: Medical simulation enables the design of learning activities for competency areas (eg, communication and leadership) identified as crucial for future health care professionals. Simulation educators and medical teachers follow different career paths, and their education backgrounds and teaching contexts may be very different in a simulation setting. Although they have a key role in facilitating learning, information on the continuing professional development (pedagogical development) of simulation educators is not available in the literature.

Objectives: To explore changes in experienced simulation educators' perceptions of their own teaching skills, practices, and understanding of teaching over time.

Methods: A qualitative exploratory study. Fourteen experienced simulation educators participated in individual open-ended interviews focusing on their development as simulation educators. Data were analyzed using an inductive thematic analysis.

Results: Marked educator development was discerned over time, expressed mainly in an altered way of thinking and acting. Five themes were identified: shifting focus, from following to utilizing a structure, setting goals, application of technology, and alignment with profession. Being confident in the role as an instructor seemed to constitute a foundation for the instructor's pedagogical development.

Conclusion: Experienced simulation educators' pedagogical development was based on selfconfidence in the educator role, and not on a deeper theoretical understanding of teaching and learning. This is the first clue to gain increased understanding regarding educational level and possible education needs among simulation educators, and it might generate several lines of research for further studies.

Keywords: continuing professional development, interviews, medical simulation, pedagogical development, simulation educator

\section{Introduction}

Technological developments are transforming professional health care expertise continuously and are challenging the individual practitioner and the field of medical education alike. Health care education is developing toward competency-based curricula in order to be responsive to the rapidly changing needs of health care and to establish a base for professional excellence as part of sustainable future health care. ${ }^{1}$

Medical simulation using manikins or standardized patients, hereafter referred to as simulation, enables the design of learning activities for basic competency areas that have been identified as crucial for future health care professionals. ${ }^{2-4}$ Comprehensive reviews support the benefits of simulation-based education (learning by experience) for learning purposes. ${ }^{5-7}$ A medical simulation session is typically conducted following a structure with three distinct phases: it starts with an introduction called briefing,

Advances in Medical Education and Practice 2017:8 99-108

99 
followed by the actual simulation, and ends with a reflection known as debriefing. ${ }^{8}$ The faculty member leading this learning activity is called a simulation educator and instructs/ facilitates during the learning session, playing a critical part in all three phases.

Development of teaching skills and understanding teaching are topics that are extensively studied by teachers who have traditional teaching roles. Ramsden described three ways of understanding teaching. ${ }^{9}$ One way is to consider teaching as transmission of knowledge, where teachers do not consider learning problems connected to teaching. Another way is to see teaching as managing students and solving their learning problems by adopting the right teaching strategy. The third way of understanding teaching in higher education is to consider students' learning and teaching as interrelated, requiring constant monitoring and adapting to students' needs for learning aids. According to Biggs, there are also three levels of thinking about teaching. ${ }^{10}$ At the first level, learning is considered to be a function of individual differences between students. At the next level, learning is considered to be a function of teaching, while at the third level, learning is the result of students' learning-focused activities.

Despite the differences in the educators' pedagogical background, three hierarchical levels have been identified in medical and dental teachers' understanding of teaching in clinical settings as described by Stenfors-Hayes et al ${ }^{11,12}$ (Figure 1).The levels of understanding learning for the specific group of medical and dental teachers are very similar to those identified by Ramsden and Biggs. Both Ramsden's and Biggs' descriptions are based on university teachers in general, while Stenfors-Hayes et al's conclusions are based on a more specific group of medical and dental teachers. A modified synthetic framework could be established using the common features of these models for the analytic purposes of the present study (Figure 2).

Even though simulation educators are faculty members just like other university or medical teachers involved in traditional learning activities, both their own education background and their teaching contexts may be very different. There are a variety of education activities for simulation educators within a given country, and the variation is even greater internationally. The majority of faculty development studies are of a quantitative character and are based on surveys with only a few mixed models. ${ }^{13,14}$ Within the specific discipline of professional learning and continuing professional development (CPD), focus has turned more toward specific activities in working life than to the understanding of professional learning and practice. ${ }^{15}$ The $\mathrm{CPD}$, hereafter

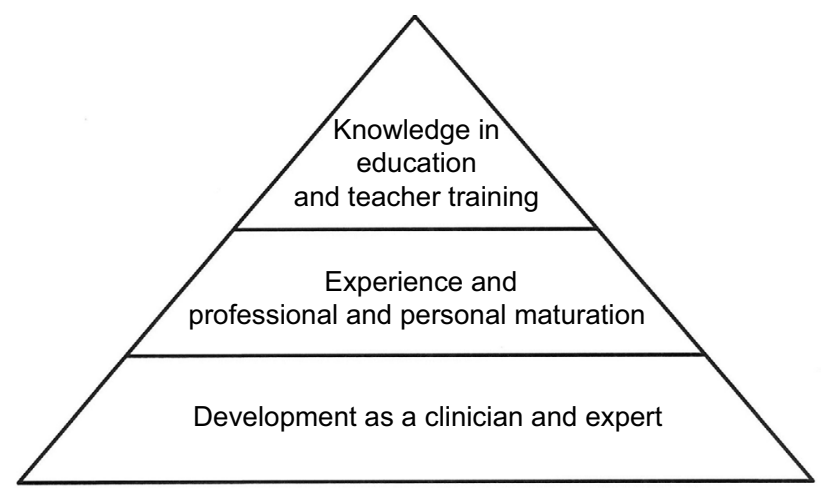

Figure I Ways of understanding teaching.

Note: Figure created based on conclusions by Stenfors-Hayes et al. ${ }^{11,12}$

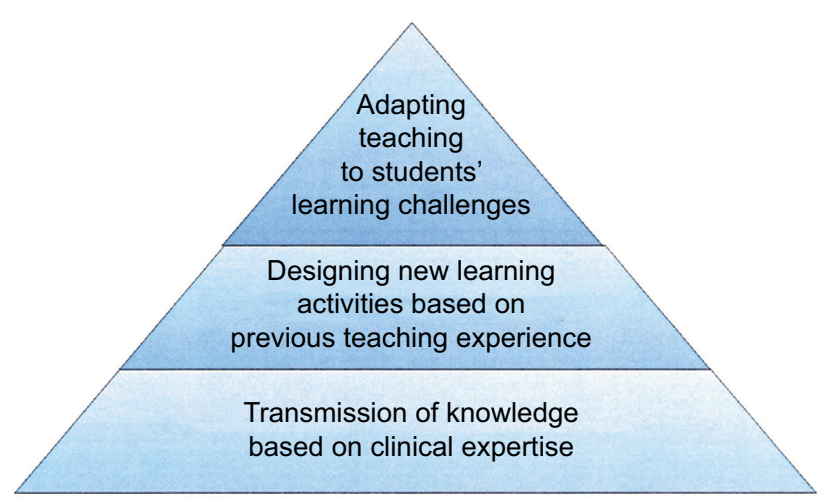

Figure 2 Expected levels of understanding teaching.

Note: Figure created and modified for simulation-based education on the basis of theories of Ramsden, ${ }^{9}$ Biggs, ${ }^{10}$ and Stenfors-Hayes et al. ${ }^{11,12}$

referred to as pedagogical development, of simulation educators has not been studied so far.

Therefore, this study aimed to explore changes in experienced simulation educators' perceptions of their own teaching skills, practices, and understanding of teaching over time, independently of eventual faculty development interventions.

\section{Methods}

\section{Design and participants}

For increased knowledge and a better understanding of the educators' pedagogical development, an explorative design with a qualitative approach ${ }^{16}$ was used. Experienced simulation educators from seven medical simulation centers in Sweden were invited to participate. A purposeful sampling strategy ${ }^{16}$ was used to recruit participants who had experience of the phenomena and to maximize variations in age, gender, clinical profession, and type of educator education. To be considered as an experienced simulation educator, a further criterion for study participation was that they had been working as an educator for at least two years, performing as an educator for a minimum of 100 simulations. All participants provided their written informed consent. The 
Regional Ethical Board of Linköping granted approval for this study (ref: 2014/204-31).

\section{Data collection}

Two experienced simulation educators from each of the seven simulation centers were personally asked about participation in the study. All accepted, and so the research team conducted 14 individual face-to-face interviews, ${ }^{17}$ each lasting between 35 and 65 minutes. All informants worked part time as simulation educators and part time as clinicians. All of them had experience of simulations with medical staff, and five of them also had experience with students. Demographic data are presented in Table 1. Data were collected between November 2014 and April 2015 by one researcher at each simulation center. All the researchers had a range of educational and working experience in terms of simulation education background and had worked both in simulation centers and in university medical and nursing education.

The interview questions were open ended and followed an interview guide to cover the central areas for the aim of the study. All interviews started with the same opening question "Can you please tell me about how you think and act in your work as a simulation educator?" After the opening question, the participants were asked to reflect on and describe their current and previous thinking and actions (Figure S1). All interviews were audio recorded, transcribed verbatim, and anonymized.

\section{Data analysis}

An inductive thematic analysis ${ }^{18}$ was used to identify and analyze patterns (themes) describing the educators' descriptions of the changes in their teaching skills, practices, and

Table I Participant characteristics

\begin{tabular}{ll}
\hline Gender, male/female, $\mathrm{n} / \mathrm{n}$ & $7 / 7$ \\
Age, years, mean (range) & $49(35-63)$ \\
Clinical profession, $\mathrm{n}(\%)$ & \\
$\quad$ Physician & $4(29)$ \\
$\quad$ Registered specialist nurse & $9(64)$ \\
Midwife & $1(7)$ \\
Educator experience, years, mean (range) & $7(4-15)$ \\
Instructor education course, $\mathrm{n}(\%)^{\mathrm{a}}$ & \\
CAMES & $9(64)$ \\
CAMST & $2(14)$ \\
CEPS & $4(29)$ \\
None & $1(1)$ \\
Experience of simulation with: & \\
Medical staff, $\mathrm{n}(\%)$ & $14(100)$ \\
Students, $\mathrm{n}(\%)$ & $5(36)$ \\
\hline
\end{tabular}

Notes: asome of the participants had completed more than one course.

Abbreviations: CAMES, Copenhagen Academy for Medical Education and Simulation; CAMST, Centre for Advanced Medical Simulation and Training; CEPS, Centre for Education in Paediatric Simulation.
Table 2 Example of a data extract and applied codes

\begin{tabular}{ll}
\hline Meaningful extract of text & Coded for \\
\hline Today I can sit down, relax, and enjoy the & Very nervous when I started \\
ongoing discussion. From the start, I was & Can focus on the participants \\
nervous and almost unable to hear what & and not myself \\
they [the simulation participants] were & Can see a difference \\
saying because I had to find out the next & \\
question to ask. So, the more confident \\
you are, the better you become. Then I \\
can focus on the participants instead of \\
on myself as an educator. There's a real \\
difference I think.
\end{tabular}

understanding of learning. In a first step, all interviews were read and re-read as whole entities so the researchers could familiarize themselves with all aspects of the data. The interviews were read by all authors individually and then discussed in the whole research group. Ideas or patterns of interest for the purpose of the study were marked in the text, and ideas about what was in the data were written down. The second step involved identifying and coding meaningful groups of text that referred to changes in the educators' acting and thinking (Table 2). Thereafter, the different codes were discussed and collated into potential overarching themes and subthemes (Figure 3). Finally, the themes were discussed and reviewed in relation to the coded groups of text and to the entire dataset. The specifics of each theme and the overall narrative were refined. The analysis involved constantly moving back and forth between the entire dataset, the coded meaningful groups of the text, and the ongoing analysis of the data. During the entire analysis process, discussions among the researchers were continually held to ensure rigor toward data and contribute to coherence of the findings.

\section{Results}

A distinct educator development was discerned over time, expressed mainly in an altered way of thinking and acting. Five themes, shifting focus, from following to utilizing a structure, setting goals, application of technology, and alignment with profession, were identified. Each theme is presented in the text below with quotations to illustrate the findings.

\section{Shifting focus}

The simulation educators described a shift in focus from context to participants. As novices, the educators had tried to control the simulation process in detail, making it difficult to observe and memorize everything that was happening. With increased experience, they took a less intervening role, relying on the participants' ability to take the lead and draw 


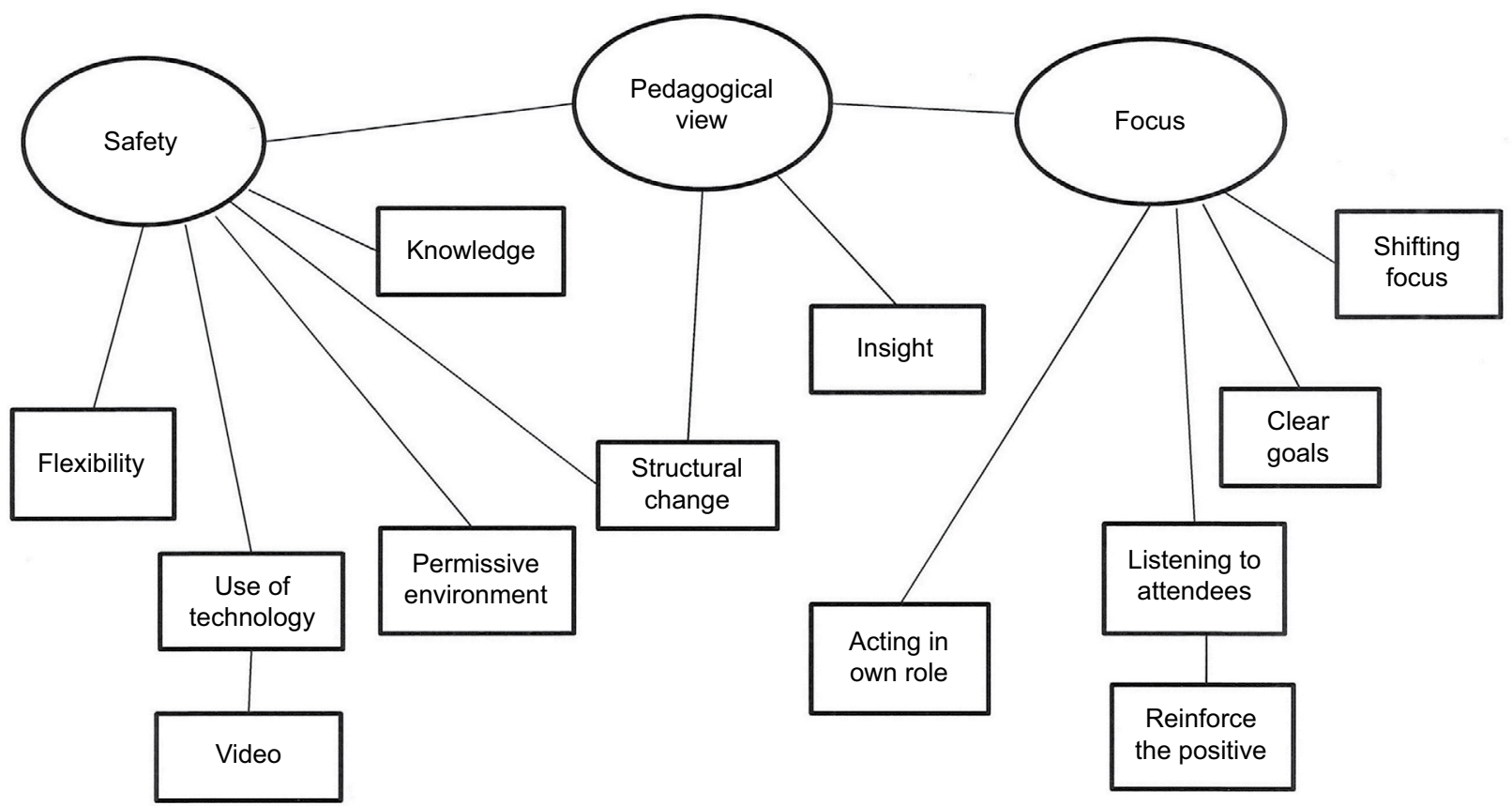

Figure 3 Initial thematic map showing three potential main themes and sub-themes.

their own conclusions. This new approach led to a more open attitude from the educator. The increased experience also led to a curiosity about the underlying causes of the participants' ways of thinking and acting during the scenarios.

Now, I can let them work for a while without directing anything. Just be standing there, reflecting on "what is happening right now?" [...] and make some notes. [Educator 5]

The educators' attitudes to teaching developed from having a focus on lecturing to encouraging participants to explain to each other.

Before I told them what to do, that this is how you assemble this equipment, and this is how you use this machine. Today I ask if there is somebody else who knows, and wants to show [...] then I can help and support. [Educator 8]

During the debriefing phase, while novices, the educators used to focus mainly on what the team had done well during the scenario. However, after gaining experience, the educators shifted focus to helping each individual participant to understand what had been going on and what they had to improve in their everyday practice.

Having the ability to set focus [during the debriefing] on issues you want to address as an instructor develops over time. [...] On the basis of the composition of the group, often a mix of personalities, you have to process these issues in a way that makes it possible for each individual participant to be conscious of their own actions. To be aware of one's strengths, but also shortcomings to improve [...]. [Educator 3]

\section{From following to utilizing a structure}

Increased experience gave the simulation educators a deeper understanding of the simulation process (briefing, scenario, debriefing). They made use of the structure rather than only adhering to it. Having confidence in the simulation process and their role as an instructor provided flexibility, which was described during the different simulation phases.

The more you simulate, the more confident you become in the instructor role. You know you are able to handle different situations, which makes it easier to let go during the scenario. You feel confident in being able to handle it afterwards. At the start, you were like a slave under an algorithm. However, I don't think it's black or white.

[Educator 5]

As novices, the educators were busy with guiding the progress during the scenarios. In contrast, the experienced educators could deliberately decide to stand back and wait for the participants to move the scenarios forward on their own. With increased experience, the educators gained skills allowing them to identify, during the scenario, what would come up for discussion during the debriefing, and therefore prepare themselves in advance.

From the start, I became really stressed if it didn't work out as I had planned, because I had made up a plan based on this scenario template. I had seen in my mind how they were going to act, and if they didn't I found it difficult. [...] I feel much more confident now, and I realize that it's important to catch what is interesting in this specific scenario, for this 
specific group. Then it's my task to lead the group through the scenario. [Educator 13]

The experienced educators had a more thoughtful approach. During the debriefing phase, they did not lead but facilitated the discussion in an effort to keep focus. The importance of developing the educator role in accordance with their own personality, although within a certain framework, was emphasized.

You get more and more confident in how you act. Today, I think I just interrupt [during the debriefing] when it's really needed. In the past, I would always have said something at the "right moment" [...] Today the group reflects on their own, and I try to help [...]. [Educator 9]

Even though the experienced educators were more confident in the role as an educator, and therefore more flexible during the simulation process, they did not describe any changes in their views of learning.

I don't think much about that [participants' learning styles], I don't know how to apply it [...] if you imagine that some people learn through observing and others through listening $[\ldots]$ I don't have great knowledge on that [...]. [Educator 10]

\section{Setting goals}

Some of the educators had always formulated goals for the simulation. Others stressed that until they had gained more experience, they did not realize the importance of setting distinct formulated goals.

\begin{abstract}
When we started, we did not reflect on the goals at all. We just created an awesome scenario. Now, we have reversed the scenario from being the coolest and funniest, to being the smallest part of this training. This process has been distinct. Today, we look at goals as instruments to highlight issues to discuss and reflect on. Today, I split up the goals and consider them as the most important part of the simulation. [Educator 14]
\end{abstract}

Educators, who from the beginning had considered that the participants should be the ones setting goals, had also revised their procedures. Previously, certain kinds of goals were formulated separately, but the educators had changed the procedure into a more flexible one.

The educators also had become conscious of the importance of communicating the goals in a way that made it easy for the participants to see that the goals should be in focus throughout all simulation phases. This insight among the participants was considered important, even though the simulation educators were responsible for running the simulation based on the goals.
I'm supposed to ascertain that they understand what I'm talking about [during the briefing]. They need to be aware of it in good time before the scenario. That this is what we are going to focus on [during the simulation session]. [...] I think I am more aware of this today than I was before. [Educator 1]

Even though the goals originally came from the organization that requested the simulation, the educators said that they could affect the design of the simulation process. They regarded it as their responsibility to split up overall goals into a few, clearly formulated ones that were possible to reach. The experienced educators stressed the importance of motivating the participants to be active during the simulation phases and to pursue the achievement of the goals. In line with this, they sometimes even asked the participants to set their own goals, choosing those they regarded as most important.

\section{$[\ldots]$ then you ask the team: "Which of these items do you want to run?" [...] Otherwise it seems to me as if there is a big risk that you have goals that aren't understood by the participants. [Educator 14]}

\section{Application of technology}

With increased experience, the educators described being more flexible in the choice of technical appliance through the scenarios. Although some of them stated that they always used video recordings during the scenario and started the debriefing section by usually watching the whole film, a majority of them described how their attitude toward the use of video had changed. Although they still saw video recordings as useful during the debriefing phase, they expressed concerns regarding the shift of focus from the participants and the content of the discussion to the film and technical issues. Their opinion was that it was easier for both participants and educators to reflect on what had taken place during the scenarios if they were not obliged to watch a video.

I think it's less and less important to use the video. Partly because it's about being able to manage the technology; both the participants and I easily lose focus on what we are searching for in the film. [Educator 2]

Others, who always showed the entire videos, still argued for the benefits of letting participants see what had taken place and emphasized instead how they developed and refined the practices of using the video.

The use of more low-fidelity manikins and medical equipment was also described. Initially, several of the educators had been fascinated by the available technical possibilities. However, with increased experience, they adjusted their 
choices according to the scenario and its specific goals and were less affected by the available range of technology.

[...] a more advanced manikin has contributed to more realism, but I will still claim that it's not the most important thing in this simulation. It is not about the technology. [Educator 12]

\section{Alignment with profession}

The educators expressed the importance of having the participants act in their own professional roles during the scenarios. They reflected on the concept of acting and concluded that it was not actually about acting in a role, it was about participants acting in the role of their own profession. They had realized that it was hard to simulate a profession in a simulation while keeping focus on the simulation goal, which was often about learning something vis-à-vis the participant's own profession. An as-if situation like this was described as counterproductive.

I have realized that the scenario wouldn't work if I put a junior doctor or registered nurse as a senior anaesthesiologist on call. It would become just a game. You cannot ask someone to live up to a role they have never had before. [Educator14]

As novice simulation educators, they had tended to follow the predetermined casting decisions even if it turned out that the group of participants was actually composed of other professions than planned. In contrast, the experienced instructors adapted the scenario to the present participants.

If we don't have all professions needed for the scenario it might be better to adjust the scenario instead of the roles.

I don't think I could have done this when I was new. Today it's easier to move away from the plans to make the scenario as good as possible for all involved. [Educator13]

\section{Meta-analysis}

The five themes above turned out to sequentially relate with one another. Being confident in the role as a simulation educator seemed to constitute a foundation for the educators' pedagogical development. An overall feeling of being confident allowed them to shift focus from themselves and their own acting to the participants and their specific needs. In a subsequent step, this new approach made them question the given structure they were following in the simulation sessions. They realized that if focusing on the participants' needs was the guiding principle, they could not run every single simulation within the same structure. Because of

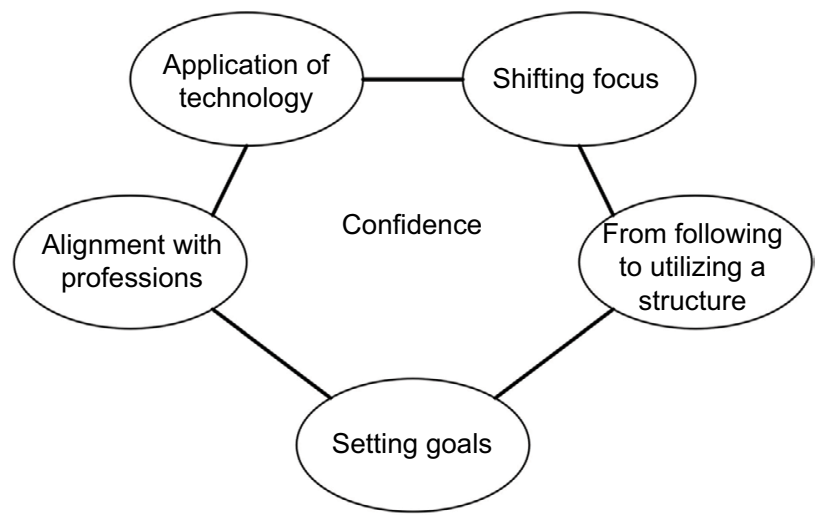

Figure 4 Final thematic map showing the final five themes sequentially related to one another.

these modifications, the educators also achieved increased understanding as regards setting goals for the simulations, using the technology in different ways, and adapting the scenarios to the actual participants (Figure 4). We consider these changes to be the result of conscious reflection by the educators.

\section{Discussion}

Faculty development approaches and their effects on medical simulation have been reported in previous studies. ${ }^{4,14}$ In this study, however, we explored experienced simulation educators' perceptions of their pedagogical development over time, which has not been done before. From the educators' descriptions, we identified five themes: shifting focus, from following to utilizing a structure, setting goals, application of technology, and alignment with profession. According to Ramsden ${ }^{9}$ and Biggs, ${ }^{10}$ teachers go through different levels of understanding teaching in their professional development. Although we found that the simulation educators shifted focus from themselves to the participants, and gave thorough descriptions of meeting the participants' needs, they did not explicitly refer to theories of learning, which is not surprising, given the possibility that they do not have basic knowledge of educational sciences. ${ }^{19}$ The lack of theoretical references may indicate an absence of theoretical reasoning connected to simulation sessions. This is supported by the fact that the simulation educators interviewed in this study worked mainly with health care personnel in their simulations and did not acquire any deeper knowledge on teaching theories during their training to become educators, as other research has shown. ${ }^{19,20}$ Nonetheless, their development followed that of teachers. The educators might see the simulation as an opportunity for the participants to practice their already existing skills, and therefore feel there is no need to discuss or reflect on learning theories. Although they have developed 
their own style in conducting a simulation session, moving from a hierarchal to a more collegial relationship between the educators and the participants, the simulation process might follow the simulation centers' practices. Seemingly, their pedagogical development, in their own interpretation, is more about being confident than gaining a deeper understanding of teaching and learning. With reference to the aforementioned meta-analysis, it would be interesting to reflect on whether being confident also means having improved as a simulation educator. Even though it seems likely that increased confidence results in enhanced competency, the study design does not allow such conclusions. It could possibly constitute a hypothesis for future research with a deeper approach. Confidence about practice might develop naturally with increased experience during the CPD. ${ }^{21}$ Nonetheless, this greater confidence among the simulation educators allowed for pedagogical insights, which was manifested as less focus on awesome scenarios and high-tech manikins, resulting in greater focus on learners' needs. Previous research has highlighted the need for developing an analytic framework helping simulation educators to facilitate learning through deeper reflection. ${ }^{22}$

Medical simulation is a widely used method for practicing communication, decision-making, and leadership ${ }^{23}$ in an effort to increase patient safety. ${ }^{24}$ The fact that medical simulation is not extensively studied with the simulation educators' development of competence in focus is somewhat surprising. Health care has become more complicated and complex, both regarding treatment principles and technical equipment. In line with this, there ought to be an increased need for a pedagogical dimension in health care. Even though national training programs have been developed for simulation educators, ${ }^{25}$ they still need increased knowledge and understanding about educational theories and its application to teaching and learning. ${ }^{19}$ Those who run medical simulations are called educators and they function as teachers. This analysis of experienced simulation educators' perceptions of their pedagogical development constitutes a basis for further research regarding the need for a specific simulation educator training program adapted to pedagogical challenges in health care simulation within the field of CPD. ${ }^{15}$

A strength of this study is that the educators had substantial experience in terms of their years as simulation educators and number of simulations, enhancing the credibility of the findings. There is no official limit to what is considered as being experienced in this context. We therefore decided to use two years as a simulation educator and 100 simulations. Furthermore, the educators had varying backgrounds and experience regarding educator courses and clinical professions and worked at medical simulation centers in different parts of Sweden. The number of participants was considered sufficient as the interviews contained rich descriptions of their development as simulation educators and no new information was obtained. Several researchers performed the interviews, which can be seen as a limitation. However, great effort was put into discussing the questions and agreeing on a common basis and preunderstanding before the interviewing started. To ensure trustworthiness, several steps were taken to ensure credibility and dependability. ${ }^{26}$ Apart from purposively selecting the participants, we scrutinized and repeatedly discussed codes, themes, and interpretations during the analysis process. Consensus was reached after several discussions in order to ensure the interpretation was based on the original meaning.

\section{Conclusion}

We conclude that experienced simulation educators' pedagogical development was based on self-confidence in the educator role, and not on a deeper theoretical understanding of teaching. Nevertheless, five themes reflecting teaching experience were delineated, namely, shifting focus; from following to utilizing a structure; setting goals; varying technology; and alignment with profession. In all the themes, a development in action could be traced. These findings provide a first step toward gaining increased understanding regarding educational level and possible educational needs among simulation educators and might generate several lines of research for further studies.

\section{Acknowledgment}

This study was supported by the Medical Research Council of Southeast Sweden.

\section{Author contributions}

ÉT conceived the idea for the study and secured ethical approval. All the authors were involved in the design of the study and conducted the interviews. RA, HH, MLSK, and ÉT were responsible for the analysis. All analytical interpretations were discussed among all authors. RA, HH, MLSK, and ÉT prepared the initial draft of the paper. MB, LC, SE, $\mathrm{MH}, \mathrm{KK}$, and IM commented on and critically revised the manuscript. All the authors approved the final version of the manuscript submitted.

\section{Disclosure}

The authors report no conflicts of interest in this work. 


\section{References}

1. Frenk J, Chen L, Bhutta ZA, et al. Health professionals for a new century: transforming education to strengthen health systems in an interdependent world. The Lancet. 2010;376(9756):1923-1958.

2. World Health Organization. Framework for Action on interprofessional Education and Collaborative Practice. Geneva: WHO; 2010.

3. Dieckmann P, Molin Friis S, Lippert A, Ostergaard D. Goals, success factors, and barriers for simulation-based learning: a qualitative interview study in health care. Simulation \& Gaming. 2012;43(5): $627-647$.

4. Topping A, Boje RB, Rekola L, et al. Towards identifying nurse educator competencies required for simulation-based learning: a systematic review and synthesis. Nurse Educa Today. 2015;35:1108-1113.

5. Issenberg SB, McGaghie MC, Petrusa ER, Gordon DL, Scalese RJ. Features and uses of high-fidelity medical simulations that lead to effective learning: a BEME systematic review. Med Teach. 2005;27(1):10-28.

6. Thistlethwaite J. Interprofessional education: a review of context, learning and the research agenda. Med Educ. 2012;46:58-70.

7. Smeby J-C. The significance of professional education. In: Jensen K, Lahn LC, Nerland M, editors. Professional Learning in the Knowledge Society. Rotterdam, The Netherlands: Sense Publishers; 2012:49-67.

8. Motola I, Devine LA, Chung HS, Sullivan JE, Issenberg SB. Simulation in healthcare education: a best evidence practical guide. AMEE Guide No. 82. Med Teach. 2013;35(10):e1511-1530.

9. Ramsden P. Learning to Teach in Higher Education. 2nd ed. Abingdon, UK: Routledge Falmer; 2003:14-18.

10. Biggs J. Teaching for Quality Learning at University. 2nd ed. Buckingham, UK: Open University Press; 2003:20-25.

11. Stenfors-Hayes T, Lindgren L, Traneus S. Perspectives on being a mentor for undergraduate dental students. J Dent Educ. 2011;15(3):153-158.

12. Stenfors-Hayes T, Hult H, Dahlgren LO. Three ways of understanding development as a teacher. J Dent Educ. 2012;16(1):151-157.

13. Steinert Y, Mann K, Centeno A, et al. A systematic review of faculty development initiatives designed to improve teaching effectiveness in medical education: BEME Guide No.8. Med Teach. 2006; 28(6):497-526.
14. McNeill J, Parker RA, Nadeau J, Pelayo LW, Cook J. Developing nurse educator competency in the pedagogy of simulation. J Nurs Educ. 2012;12:685-691.

15. Reich A, Rooney D, Boud D. Dilemmas in continuing professional learning: learning inscribed in frameworks or elicited from practice. Stud Contin Educ. 2015;37(2):131-141.

16. Polit D, Beck C. Nursing Research: Generating and Assessing Evidence for Nursing Practice. Philadelphia, PA: Wolters Kluwer/Lippincott Williams \& Wilkins; 2011.

17. Kvale S, Brinkman S. Interviews: Learning the Craft of Qualitative Research Interviewing. Thousand Oaks, CA: Sage Publications; 2009.

18. Braun V, Clarke V. Using thematic analysis in psychology. Qual Res Psychol. 2006;3(2):77-101.

19. Pasquale SJ. Educational science meets simulation. Best Pract Res Clin Anaesthesiol. 2015;29:5-12.

20. Katoue MG, Iblagh N, Somerville S, Ker J. Introducing simulationbased education to healthcare professionals: exploring the challenge of integrating theory into educational practice. Scott Med J. 2015;60(4):176-181

21. Nicolson P, Burr J, Powell J. Becoming an advanced practitioner in neonatal nursing: a psycho-social study of the relationship between education preparation and role development. J Clin Nurs. 2055;14: $727-738$.

22. Husebo D, Dieckmann P, Rystedt H, Friberg F. The relationship between facilitators' questions and the level of reflection in the post-simulation debriefing. Simul Healthc. 2013;8(3):135-142.

23. Gjeraa K, Moller TP, Ostergaard D. Efficacy of simulation-based trauma team training of non-technical skills. A systematic review. Acta Anaesthesiol Scand. 2014;58:775-787.

24. Zendejas B, Brydges R, Wang AT, Cook DA. Patient outcomes in simulation-based medical education: a systematic review. J Gen Intern Med. 2013;28(8):1078-1089.

25. Nestel D, Bearman M, Brooks P, et al. A national training program for simulation educators and technicians: evaluation strategy and outcome. BMC Med Educ. 2016;16:25

26. Lincoln YS, Guba EG. Naturalistic Inquiry. Beverly Hills, CA: Sage; 1985. 


\section{Supplementary material}

Instructions to the interviewer

The "bold" headings include the issues to be "covered" during the interview. Under each heading there are key words/questions, to help you to cover all aspects of events during a simulation session. Seek to perform the interview more like a conversation. The order of the different headings and key words may vary from interviewee to interviewee. Instead of asking direct questions, try to help the interviewee to deepen/develop the narrative/description. Remember that the purpose is to explore how the experienced simulation educator thinks and acts today, compared with when he/she was a novice.

\section{Initial question}

Can you please tell me how you think and act in your work as a simulation educator?

\section{What thoughts do you have about}

- Briefing

○ Information about the situation

○ Information about roles/tasks

- Information about technology and manikins

Did you think in the same way when you started to work as a simulation educator?

- How to act as a simulation educator during the simulation

- How active are you as a simulation educator?

○ During which phase/phases do questions appear?

○ How do you act on improper behavior?

Did you think in the same way when you started to work as a simulation educator?

\section{- Debriefing}

$\bigcirc$ The need for debriefing

- Using video recording

○ Given algorithms or flexibility

The length of the debriefing

○ The simulation educator's acting during the debriefing

Did you think in the same way when you started to work as a simulation educator?

\section{What are your views on}

- Learning

○ Participant's learning styles and the importance of these

○ How to support learning

- How do you know that learning has occurred?

- The need of goals for the simulation

- How should goals be formulated?

○ Who formulates goals/objectives in a simulation?

Figure SI Interview guide concerning experienced simulation educators' changes in teaching skills, practices and understanding of learning 
Advances in Medical Education and Practice

Dovepress

\section{Publish your work in this journal}

Advances in Medical Education and Practice is an international, peerreviewed, open access journal that aims to present and publish research on Medical Education covering medical, dental, nursing and allied health care professional education. The journal covers undergraduate education, postgraduate training and continuing medical education

including emerging trends and innovative models linking education, research, and health care services. The manuscript management system is completely online and includes a very quick and fair peer-review system. Visit http://www.dovepress.com/testimonials.php to read real quotes from published authors.

Submit your manuscript here: http://www.dovepress.com/advances-in-medical-education-and-practice-journal 